\title{
Flexible bronchoscopic removal of a three piece foreign body from a
}

\section{child's bronchus}

\author{
Mehta $D^{1}$, Mehta $C^{2}$, Bansal $S^{1}$, Singla $S^{1}$, Tangri $N^{1}$
}

1. MM Institute of Medical Science and Research,Ambala

2. Mehta Clinic and Nursing Home, Yamunanagar

\section{CASE REPORT}

Please cite this paper as: Mehta D. Flexible bronchoscopic removal of a three piece foreign body from a child's bronchus. AMJ 2012, 5, 4, 227-230. http://doi.org/10.21767/AMJ.2012.1127

Corresponding Author:

Name: Dinesh Mehta

Address: 406, Model colony, Yamunanagar, Haryana, India.

Email@address: drdineshmehta@gmail.com

\section{Abstract}

Foreign body aspiration can be a life-threatening event especially in young children because they have smaller diameters of airway lumen, moreover, the delay in the diagnosis and subsequent therapeutic intervention can further increase the risk of morbidity. ${ }^{1,2}$ A retained foreign body can result in inflammatory response and granulation tissue formation around the object which make the foreign body removal difficult. ${ }^{3}$ In such situations surgical intervention is usually needed but with interventional pulmonology modalities we can restrict the need for surgery. ${ }^{4}$ Rigid bronchoscopy under general anaesthesia is the gold standard of diagnosis and management of foreign body aspiration. ${ }^{1}$ However, nowadays flexible bronchoscopy is more widely available and most pulmonary physicians are trained in its use so it can be used to remove such foreign bodies. We hereby report a case of a neglected foreign body which remained in the bronchus of a child for 11 days, successfully removed by flexible bronchoscopy.

Key Words

Foreign body; flexible bronchoscopy

\section{Background}

Many deaths in children are caused by aspiration of foreign bodies into the tracheobronchial tree. Delay in the diagnosis may increase morbidity and mortality, ranging from lifethreatening airway obstruction to recurrent infection and wheezing or coughing. Mere history of foreign body aspiration is a strong indication of bronchoscopic evaluations even in the absence of physical and radiological findings ${ }^{5}$. Rigid bronchoscopy is the intervention of choice for the management of bronchial foreign bodies in children. ${ }^{6}$ The ability to control the airway, ventilate, and the availability of a wide variety of extraction instruments have established rigid bronchoscopy as a safe method to remove foreign bodies in children. Although paediatric flexible bronchoscopes have been used for several decades in the diagnosis and treatment of various respiratory disorders in children, a review of the literature revealed a paucity of published data on the use of flexible bronchoscopy to extract foreign bodies in children. The bronchoscopy section at the Mayo Clinic, Rochester, has previously reported ${ }^{7}$ the experience with successful removal of foreign bodies with a paediatric flexible bronchoscope in six children. There have been sporadic reports of using the flexible bronchoscope to retrieve airway foreign bodies in children when no facility for rigid bronchoscopy or surgery was available but an expert flexible bronchoscopy facility was present. Such reports provided us with the courage to undertake the challenge of removing the foreign body from the bronchus of this four-year-old child using flexible bronchoscopy.

\section{Case details}

A four-year-old male was referred to our tertiary care centre with history of inhalation/aspiration of a plastic foreign body, a whistle, 11 days previous. The patient weighed $12 \mathrm{~kg}$ and was of average build, playful and interested in his surroundings. The patient had minimal chest discomfort with restlessness and the parents reported hearing a whistling sound on coughing and while sleeping. Routine body fluid tests were normal with a normal chest radiograph which did not reveal any foreign body. X-ray of the soft tissues neck was also normal. CT scan of the chest 
was not done in view of the descriptive history and relative stability of the patient's condition.

Figure 1: Three parts of the whistle removed from patient's right middle lobe of lung

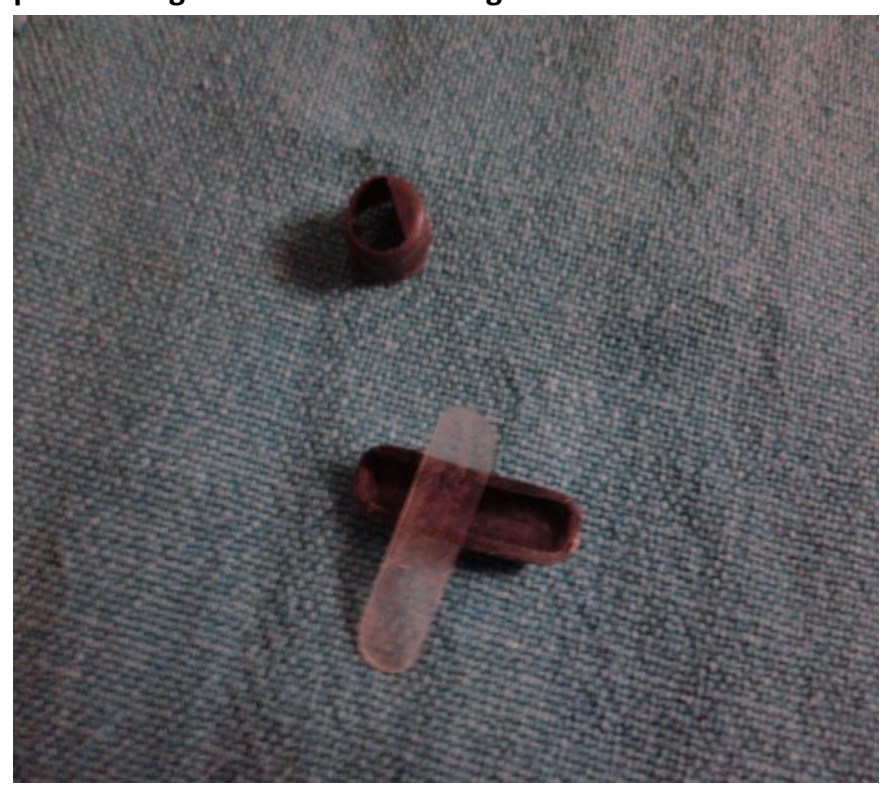

Bronchoscopy was performed because of clinical suspicion of foreign body aspiration. The foreign body was visualised in the right middle lobe bronchus. The middle parts of the whistle were grasped by the foreign body forceps and removed while the outer part of the whistle which was nearly the same diameter as the bronchus wall was adherent to the wall and there was formation of granulation tissue. Passing the forceps inside through the whistle and then opening it and retracting it dislodged a small portion of the border of the whistle which was grasped by the crocodile forceps and rotated which broke the granulation tissues gradually. The foreign body was then removed (Figure 1) with the bronchoscope as a single assembly keeping the foreign body in sight and taking care that it did not dislodge at the level of vocal cords and obstruct the trachea. Flexible bronchoscopy was performed under general anaesthesia. The patient did not experience respiratory distress during the procedure. The saturation of oxygen $\left(\mathrm{SpO}_{2}\right)$ was kept above $92 \%$ throughout most of the procedure with the help of supplemental oxygen, however, the patient experienced transient hypoxia once and saturation dropped to $85 \%$ necessitating removal of the bronchoscope. Oxygen saturations quickly returned to normal and the procedure was successfully completed. There was no observed complication, however, a check bronchoscopy immediately after the procedure revealed slight bleeding at the site of granulation tissue with minimal oedema. Time taken for the procedure was approximately 40 minutes. The whistling sound and chest discomfort disappeared completely after the procedure. The patient was discharged the next day in stable condition.

\section{Discussion}

Traditionally, it is the rigid bronchoscope which has been used for the removal of foreign bodies in children. ${ }^{9}$ The noteworthy advantages of the rigid bronchoscope, when used in children is its ability to function as an endotracheal tube ensuring control of the airway and as a conduit through which the foreign body can be removed. ${ }^{10-12}$ However, the equipment and technique are not available in all medical centres. In contrast, flexible bronchoscopy is widely available and most pulmonologists are well versed with the use of the flexible bronchoscope. The standard flexible bronchoscope has been used increasingly in the treatment of foreign bodies in adults. ${ }^{13,14}$ Some flexible bronchoscopes have large channels for suctioning of smaller foreign bodies from the distal airways. Some flexible bronchoscopes have the capacity to remove almost any type of foreign body in adults because of the availability of several ancillary instruments. ${ }^{15}$ Furthermore; the flexible bronchoscope allows the retrieval of foreign bodies that have migrated deeper into the subsegmental bronchi.

In contrast to the standard flexible bronchoscope used in adults, the paediatric flexible bronchoscope may interfere with ventilation to a significant degree. To avoid the complication of ventilatory difficulty, an ultrathin bronchoscope (outer diameter of $2.2 \mathrm{~mm}$ ) may be used ${ }^{16}$ in the present case; the foreign body being a whistle allowed the passage of air through the central hollow portion and did not hamper gas exchange or cause atelectasis, explaining the reason for relative stability of the child. As the whistle was made of radiolucent material (plastic) and overlaid the hilar shadow, it was barely visible on plain chest radiograph.

Cases have been reported in which foreign bodies that had migrated distally could not be extracted by rigid bronchoscopy, but were successfully removed by flexible bronchoscopy. ${ }^{7}$ Our case was similar, where the foreign body migrated to right middle lobe to wedge there and we removed it successfully after slight manipulation using a flexible bronchoscope. There was no apparent complication associated with the procedure. Even large foreign bodies can be captured and removed by utilising appropriate retrieval aids. The ureteral forceps and baskets used to extract the foreign bodies are externally coated with Teflon, which permits the frictionless passage of these instruments through the narrow suction channel of the paediatric flexible bronchoscope. The importance of the operating theatre assistant cannot be understated as they have control over the forceps or the basket. The assistant is instructed not to let go of the foreign body and not to close 
the basket or forceps too tight which may cause the foreign body to slip out of the capturing instrument. Loss of control over the foreign body during the retrieval attempt is more likely to occur when the foreign body is being pulled through the narrow subglottic space and through the vocal cords. ${ }^{17}$ This narrow space can shear off the foreign body and lead to acute obstruction of the upper airway by the foreign body. If the foreign body is lost during extraction, the bronchoscopist should immediately reintubate the patient and then reattempt retrieval. In case the foreign body is in the glottis, it should be pushed back down into one of the lungs so that adequate ventilation and oxygenation can be provided. Removing the foreign body through the endotracheal tube eliminates the possibility of losing the object at the glottis. Most pulmonologists are trained in flexible bronchoscopy but have no training or experience in rigid bronchoscopy. As a result, surgical specialists trained in rigid bronchoscopy have treated almost all documented airway foreign bodies in children. This maybe true even after the foreign body is identified by flexible bronchoscopy by a physician, Instead of immediate flexible bronchoscopic removal, the child is scheduled either for rigid bronchoscopy at a separate session in the same medical facility or transferred to another facility with rigid bronchoscopy facility. With flexible bronchoscopy two separate procedures for the same problem can beavoided

Through this report we wish to state that flexible bronchoscopy to which most of the pulmonologists in India are trained, is a good tool for the removal of even segmental and subsegmental foreign bodies in children and should be used as a first line of management obviating the routine practice of referring to higher surgical centres or centres with rigid brochoscopy which are few and faraway.

\section{References}

1. Farrell PT. Rigid bronchoscopy for foreign body removal: anaesthesia and ventilation. Paediatr Anaesth. 2004; 14: 84 $-89$.

2. Tu CY, Chen HJ, Chen W, Liu YH, Chen $\mathrm{CH}$. A feasible approach for extraction of dental prostheses from the airway by flexible bronchoscopy in concert with wire loop snares. Laryngoscope. 2007; 117: 1280 - 1282.

3. Walters PR. Foreign body lodged in lung and removed after eleven years by bronchoscopy. Cal State J Med.1918; 16(1):42-43

4. Willett LL, Barney J, Saylors G, Dransfield M. An unusual cause of chronic cough. Foreign body aspiration.J Gen Intern Med. 2006; 21: c1 - c3.
5. Macgowan WAL. Inhaled foreign bodies in a series of Sudanese Thorax (1959), 14, 181

6. Schmidt $H$, Manegold B.C. foreign body aspiration in children. Surgical Oncol.14;7:644-648

7. Toy-related injuries among children and teenagers, 1996. MMWR Morb Mortal Wkly Rep 1997; 46:1185-1189

8. Mantor PC, Tuggle DW, Tunell WP. An appropriate negative bronchoscopy rate in suspected foreign body aspiration. Am J Surg 1989; 158:622-624

9. Castro M, Midthun DE, Edell ES, et al. Flexible bronchoscopic removal of foreign bodies from pediatric airways. J Bronchol 1994; 1:92-98

10. Wood RE. Flexible bronchoscopy to remove foreign bodies in children-yes, may be- but [editorial]. J Bronchol 1994; $1: 87$

11. Pasaoglu I, Dogan R, Demircin M, et al. Bronchoscopic removal of foreign bodies in children: retrospective analysis of 822 cases. Thorac Cardiovasc Surg 1991; 39:95-98

12. Prakash UBS, Midthun DE, Edell ES. Indications for flexible versus rigid bronchoscopy in children with suspected foreignbody aspiration. Am J Respir Crit Care Med 1997; 156:1017-1019

13. Prakash UBS, Cortese, DA. Tracheobronchial foreign bodies. In. Prakash UBS, ed. Bronchoscopy. New York, NY: Raven Press; 1994; 253-277

14. Prakash UBS, Holinger LD. Pediatric rigid bronchoscopy In. Prakash UBS, ed. Bronchoscopy. New York, NY: Raven Press; 1994; 329-343

15. Limper AH, Prakash UBS. Tracheobronchial foreign bodies in adults. Ann Intern Med 1990; 112:604-609 16. Karen LS, Udaya BSP, David EM, Edell EL, Utz JP, Mark JB.Flexible Bronchoscopic Management of Airway Foreign Bodies in Children. Chest 2002; 121; 1695-170.

17. Lan RS, Lee CH, Chiang YC, Wang WJ. Use of fiberoptic bronchoscopy to remove tracheobronchial foreign bodies in adults. Am Rev Respir Dis 1989; 140(6):1734-1737

\section{ACKNOWLEDGEMENTS}

None

\section{PEER REVIEW}

Not commissioned. Externally peer reviewed.

\section{CONFLICTS OF INTEREST}

The authors declare that they have no competing interests

\section{FUNDING}

No external funding. Self funded study.

\section{PATIENT CONSENT}

The authors, Dr. Dinesh Mehta, Dr. Chavi Mehta, Dr. Sachin Bansal, Dr. Sulbha Singla, Dr. Nitin Tangri declare that: 
Australasian Medical Journal [AMJ 2012, 5, 4, 227-230]

1. They obtained written, informed consent for the publication of the details relating to the participants(s) in this report.

2. All possible steps have been taken to safeguard the identity of the participant(s).

3. This submission is compliant with the requirements of local research ethics committees. 